\title{
ANGLICISMOS USADOS EN NARRACIONES COSTARRICENSES EN EL FÚTBOL
}

\author{
Marjorie González Gómez
}

\begin{abstract}
RESUMEN
La investigación se basa en la estrecha relación entre cultura y lenguaje. Tiene carácter lexicográfico exclusivamente. Recopila y describe el léxico utilizado por una muestra de narradores deportivos costarricenses. El material se obtuvo de grabaciones hechas de octubre de 1988 a abril de 1989.
\end{abstract}

\begin{abstract}
This research is based on a close relationship between language and culture. It is exclusively lexicographic. It compiles and describes the lexicon used by a group of sports Costa Rican comentators. The material was obtained from records done from October 1988 to April 1989.
\end{abstract}

\section{Introducción}

\subsection{Justificación}

Se ha decidido trabajar con los anglicismos utilizados por los narradores deportivos costarricenses en el fútbol por considerar que es de importancia para las investigaciones del español en Costa Rica; interesa cuantificar y categorizar estos vocablos. Además, esta investigación no se ha llevado a cabo antes, de ahí lo apremiante de su realización.

Nos proponemos presentar un corpus de textos narrativos sobre el deporte en mención y elaborar un inventario de los anglicismos presentes en esos textos, con su correspondiente definición lexicográfica, señalamiento de etimología y, además, buscamos establecer la tipología de esos anglicismos con un material recogido del mes de octubre de 1988 y abril de 1989.

\subsection{Objetivos}

1. Recoger un corpus representativo de narraciones en deportes practicados en Costa Rica (fútbol, en este caso) para identificar los anglicismos presentes en ese corpus.

2. Categorizar los anglicismos de acuerdo con la tipología del préstamo lingüístico siguiendo a Helmut Lüdtke. 
3. Definir lexicográficamente cada uno de los rubros identificados, según el método empleado por G. Haensch de la Universidad de Ausburgo, República Federal de Alemania.

4. Contribuir en la elaboración de un nuevo diccionario del español costarricense, mediante un aporte en el área del deporte.

\subsection{Definición del anglicismo}

La Real Academia Española define el término anglicismo de la siguiente forma: "Giro o modo de hablar propio y privativo de la lengua inglesa //2. Vocablo o giro de esta lengua empleado en otra. //3. Empleo de vocablos o giros ingleses en distinto idioma". Sin embargo, estas acepciones para la presente investigación son poco precisas y no permiten llegar al punto central de nuestro propósito. Es necesario, por lo tanto, a fin de dar un enfoque más objetivo, enmarcar el anglicismo dentro de una categoría más amplia. Esto se llevará a cabo si se analizan los anglicismos como un fenómeno, entre los muchos existentes, de lo que se ha llamado "préstamos", en los términos según los analiza Helmut Lüdtke (1974: 21-5).

\subsection{Penetración de los anglicismos}

En la historia de la lengua castellana, en lo concerniente al siglo XX, se ha marcado una gran afluencia léxica con origen en el idioma inglés. El inglés es hoy en día la más difundida de las lenguas occidentales, de ahí la influencia que ejerce en otras lenguas naturales, especialmente en los ámbitos de la experiencia humana, que se relacionan con la ciencia, la tecnología y los deportes, razón por la cual distintas variedades de lenguaje muestran numerosos vocablos de procedencia inglesa.

Es importante aclarar que en la presente investigación se han tomado como anglicismos todos aquellos elementos que han llegado directamente del inglés, sin tomar en cuenta su etimología primigenia.

El inglés, por su condición expansiva en nuestra época, tiene una gran fuerza de infiltración en el léxico, habiendo influido también en los otros componentes de la lengua.

En el siglo XVIII y parte del XIX, el castellano tuvo gran influencia francesa. Pero en el XX el galicismo cede y comienza el reinado del anglicismo. ¿Por qué? El galicismo contaba casi sólo con el libro como única vía de penetración; el inglés, por el contrario, tiene diversos recursos, entre los cuales los más poderosos son los medios de comunicación: las agencias noticiosas, la radio, la prensa, la televisión, la industria, la ciencia, la cinematografía, los viajes, las estrechas relaciones internacionales y sociales, las competencias atléticas a nivel internacional, todo esto, sumado a la gran preponderancia económica, científica y política que tienen algunos países de habla inglesa en el mundo entero. Por lo tanto, no es de extrañar que el inglés sea hoy la lengua más difundida y, por ende, casi es obligatorio mantener una relación directa e indirecta con ella (cfr Alfaro: 1950, prólogo).

En el caso particular de Costa Rica, su posición geográfica ha favorecido que gran cantidad de costarricenses se desplacen por diversas razones a los Estados Unidos de América: placer, trabajo, competencias atléticas, todo lo cual redunda en una adquisición de vocablos ingleses. 
En el campo conceptual que nos interesa, el de los deportes, es importante recalcar que el fútbol se ha originado en países de habla inglesa. El fútbol, nacido en Inglaterra, fue traído a Costa Rica por los ingleses que fundaron la Costa Rica Light and Traction (cfr. Salas 1951: 21-5).

Los deportes han sido, sin duda, una fuente prolífera de anglicismos. De las modernas agencias noticiosas, las más grandes pertenecen a países de habla inglesa, transmiten los acontecimientos atléticos más importantes y, en muchos casos, los mensajes son recibidos en inglés por traductores que, presionados por el tiempo y sin atender cuidadosamente los usos castellanos transmiten la información por medio de textos portadores de elementos lingüísticos de la lengua originaria; de esta manera muchos anglicismos se difunden e incorporan en el español: léxico, campo semántico y construcciones anglicadas.

\subsection{Reseña histórica}

\subsubsection{Orígenes del fútbol}

Mientras se juegue el fútbol, habrá pueblos que se atribuyan su cuna. El último intento de una reivindicación procede de Yugoslavia, en donde fue realizada con tanto fervor como falta de fundamento. Los florentinos insisten desde hace tiempo, en que el Calcio in Livrea, que según dicen, se jugaba en la plaza de la Santa Cruz cuando las tropas de Carlos V asediaban la ciudad, en el siglo XVI, constituye un precedente del fútbol moderno. Antiguos dibujos muestran que los chinos jugaban una especie de fútbol, hace miles de años, con una pelota de mimbre.

Incluso, se ha sugerido que la forma más primitiva de fútbol tuvo un origen macabro, pues consistía en una celebración de las victorias bélicas en la que se habrían utilizado como balón las cabezas de los enemigos decapitados. Tal vez fuera así, pero esta teoría es tan poco sólida como cualquiera de las demás. Lo cierto es que, a pesar de que durante la época fascista los italianos no cesaron de pregonar la primacía del Calcio in Livrea, este juego había estado olvidado durante muchos años y fue resucitado en el siglo XX por los fascistas, como arma de propaganda, mucho después de que el fútbol asociado ya estaba firmemente arraigado.

El fútbol moderno, como tantos otros deportes: el tenis, el criquet, el ciclismo, el rugby, el hockey, entre otros, incluso el atletismo, es una invención británica, un producto de la época victoriana, extraordinariamente fructífera para las "public schools" inglesas. En opinión de un destacado sociólogo de la historia, en un principio, el fútbol constituía un juego o pasatiempo propio de las clases bajas y fue dignificado por las "public schools" inglesas para acabar volviendo a las masas trabajadoras al surgir el profesionalismo. Podría recordarse, a este respecto, que la alta sociedad británica rechazó, horrorizada, esta nueva "forma de vulgaridad", mientras en el resto de Europa y en América del Sur, no existieron prejuicios sociales ni barreras de este tipo que dificultaran el desarrollo del fútbol.

La característica fundamental del fútbol inglés en sus primeros tiempos era la "brutalidad". En los archivos parroquiales se han hallado centenares de muertes violentas: en un caso, ocurrido en un encuentro de campesinos, dos jugadores fueron asesinados a cuchilladas por un hombre cuyos hijos militaban en el equipo contrario. 
Picford y Gibson, en su amena obra de cuatro volúmenes Association football and the men who made it, aparecida en 1906, aseguran la existencia de un decreto, promulgado por Eduardo II en 1314, el cual prohibía el juego donde las carreras realizadas tras gruesas pelotas provocaban grandes tumultos en la ciudad. Por lo tanto, se mandaba y prohibía, en nombre del Rey y bajo pena de prisión, practicar en lo sucesivo tales juegos en la ciudad de Glasgow.

Menciona Fitz-Stephen que, en fecha tan remota como 1175, los escolares de Londres empezaron a jugar al fútbol el martes de carnaval y siguieron haciéndolo otros muchos martes de carnaval en años sucesivos.

De nuevo, tenemos la impresión de que el fútbol, este fútbol primitivo, era una excusa para la violencia. Tal vez no debiéramos sorprendernos demasiado, porque la violencia nunca ha podido ser arrancada del todo de este deporte, más bien parece constituir un elemento esencial de otros, como el fútbol americano, el rugby de trece y el rugby de quince.

Otro monarca inglés que prohibió este deporte fue Ricardo II, quién promulgó un nuevo decreto contra el fútbol en 1389, pues se mostraba contrario a él porque hacía disminuir la práctica del tiro con arco. Enrique IV reafirmó el anterior decreto en 14O1, lo cual permite suponer que su cumplimiento distó mucho de ser total, y fue promulgado de nuevo bajo los Tudor, durante el reinado de Enrique VIII. Jacobo I de Escocia decretó que nadie podría jugar al fútbol en lo sucesivo, so pena de castigo, pero en 1497 el tesorero mayor de su sucesor, Jacobo IV, registró la compra de dos pelotas para el rey, destinadas a un partido que debía jugarse en abril en la ciudad de Stirling. Durante el reinado de Isabel I, el juego del fútbol aún no había desaparecido y continuaba siendo tan bárbaro como antes. En 1572 la reina prohibió que se jugara al fútbol en la ciudad de Londres; un escritor contemporáneo, Sir Thomas Elyot, se quejaba de que "el fútbol era un pasatiempo impropio de un caballero, ya que el juego no proporcionaba el más mínimo placer, y era causa de furia bestial y de violencias".

Al leer esto, ¿no es posible establecer un paralelismo entre los violentos orígenes del fútbol inglés y la barbarie que muestran los actuales fanáticos británicos de este deporte, barbarie que presenta caracteres a la vez de ritual y de clan? Sin duda ellos no toman parte del deporte, como hacían sus antepasados, pero tal vez no estaría de más aceptar que ha tenido lugar un proceso de disgregación, y que en buena parte ha quedado limpio de violencia a la par de que la necesidad de esta última ha sido satisfecha, por así decirlo, de manera periférica. Los jóvenes fanáticos se han encargado de ello.

A pesar de todo, el juego fue progresando. El diario de Samuel Pepys, escrito durante el invierno de 1655, en el mes de enero, dice que las calles estaban "llenas de partidos de fútbol". Cuarenta y tres años después, en la región noroeste de Inglaterra, los magistrados de Manchester deploraban lo que ellos describían como "el ilegal juego de fútbol en las calles de la mencionada población, que destrozaba muchas ventanas de ciudadanos, así como los cristales de sus escaparates, además de provocar graves excesos". Pueblos enteros competían contra otras poblaciones, siendo lo que podríamos llamar porterías los confines de cada localidad.

Es indudable que el fútbol, por muy duro y peligroso que pudiera ser, era extraordinariamente popular entre los jóvenes trabajadores ingleses, y se comprende fácilmente que las reglas que lo regulan hoy día tuvieran gran disparidad. Fue reglamentado por primera vez en 1863; el primer encuentro con luz artificial se jugó en 1887 en Sheffield. El fútbol es hoy el juego deportivo más extendido en el mundo (cfr. Enciclopedia Salvat de los Deportes Vol. 1 1976: 61-3). 


\subsubsection{El fútbol en Costa Rica}

En 1883, se fundó en Costa Rica la Compañía Eléctrica de Costa Rica, empresa precursora de la que hoy es la Compañía Nacional de Fuerza y Luz. Los dueños de la Compañía Eléctrica de Costa Rica no pudieron obtener apoyo de los capitalistas nacionales. Para algunos el negocio no tenía "pies ni cabeza". Entonces, la Compañía fue vendida en 1889 a la Costa Rica Light and Traction Co., que llegó a ser conocida simplemente como la "Compañía del Tranvía", una empresa de capital inglés, lo cual hizo posible que ciudadanos de esa nacionalidad vinieran a San José a construir el tranvía. Con ellos vino el fútbol.

El 14 de julio de 1890 la línea del tranvía quedó instalada en La Sabana hasta la terminal del Oeste, que estaba ubicada al costado norte del antiguo Colegio La Salle, donde hoy está la sede del Ministerio de Agricultura y Ganadería. Allí jugaban al fútbol los ingleses que vinieron a construir el tranvía, a los cuales poco a poco se fueron sumando los costarricenses, hijos de los oligarcas cafetaleros que habían sido enviados a Londres, mercado cafetalero por excelencia, a estudiar. Poco a poco, los juegos se fueron haciendo famosos y por ahí de 1905 tenían una gran concurrencia de público. Los costarricenses jugaban en la Plaza de San Juan del Murciélago, hoy San Juan de Tibás, donde vivían algunas familias que habían hecho fortuna con el café.

Por el año de 1904 -1905 se fundó el Club Sport Cartaginés y poco tiempo después, el 14 de julio de 1906, el Josefino. Los costarricenses invitaron luego a otros grupos para formar una federación (cfr Salas 1951: 19-26).

\section{Estado de la cuestión}

Las investigaciones sobre el componente léxico del español en Costa Rica tienen una tradición de por lo menos un siglo, habiendo sido efectuadas, en su mayoría, con criterios preceptivos (Sánchez Corrales, 1988).

En lo que concierne a anglicismos, no ha habido trabajos significativos, con excepción de la obra de Zúñiga Tristán (1976), El anglicismo en el habla costarricense, que, en opinión de Sánchez Corrales, "es un inventario amplio de anglicismos que muestra la erudición de la autora. Si bien la investigadora dice que su estudio se basa en "el lenguaje oral de nuestro pueblo" (Zúñiga 1976: 15), al no emplearse con rigurosidad criterios de frecuencia, productividad, riqueza semántica, distribución geográfica (Salas y otros: 1977), la investigación tomada en su conjunto produce la impresión de que el español en Costa Rica es anglicado por excelencia, lo cual es falso". Igualmente, existen unos artículos publicados por don Cristián Rodríguez en la página quince del periódico La Nación durante los años 70 al 82, y la tesis de la licenciada Zuray Mora Cárdenas (1985): Cristián Rodríguez, los anglicismos y el español de Costa Rica, en la cual la autora investiga el aporte crítico que don Cristián Rodríguez hizo al español de Costa Rica, con el fin de contribuir con una recopilación de todo ese valioso material publicado durante casi treinta años en varios periódicos locales, especialmente $\mathrm{La} \mathrm{Na}$ ción. Es importante notar que en la tesis de la licenciada Mora Cárdenas, no aparece ninguno de los anglicismos encontrados en las narraciones deportivas, lo cual demuestra que la presente investigación es un aporte importante para aquellos que estudian el español, además de ofrecer una opción para continuar esta clase de estudios en Costa Rica. Por lo demás, lo único que existe son artículos esporádicos en la prensa. 
Como puede notarse, no hay ningún trabajo sobre el aporte léxico del inglés en el español de Costa Rica, en el campo del deporte: fútbol.

\section{El préstamo lingüístico}

Los préstamos están unidos inseparablemente por su naturaleza a la esencia y cambio posterior de toda lengua. Sus causas se pueden encontrar en la necesidad comunicativa que todo individuo posee, también como resultado de nexos históricos, socio-políticos, geográficos, sobre todo, por la necesidad de comunicación que existe entre los hablantes. Como lo indica Martínez Hernández en el prólogo del libro Historia del léxico románico (1974: 7):

\footnotetext{
La sucesión histórica de las distintas situaciones lingüísticas se ofrece como resultado de profundas conmociones políticas y culturales. Pensemos, por ejemplo en lo que para la renovación del léxico significa el Cristianismo, la Invasión de los bárbaros o el Renacimiento. Es un mundo de continuos cambios. Los vocablos pasan de unas lenguas a otras en virtud de " préstamos". Y no solo se prestan materias, sino procedimientos formales y hasta matices de sentido. Cada palabra, además de atenerse a ciertas leyes, puede tener su historia particular. Hoy día, ¿cuántos préstamos deberemos al inglés ? Y los esqueletos de las palabras, que no son otra cosa que las siglas, ¿no nos cercan por todos los lados, gesticulantes? Nada inventamos: son dos características de nuestro léxico actual".
}

En la presente investigación se usará como fundamento el concepto de "préstamo" que describe Helmut Lüdtke en su libro Historia del léxico románico. Según Lüdtke, el préstamo lingüístico ocurre cuando: " dadas dos lenguas A y B, A influye léxicamente en B o viceversa" (1974: 22). Al hablar de préstamos, según él, se comprenden los conceptos de: préstamos de vocabulario, préstamos de formación y préstamos semánticos, conceptos que se desarrollarán en el capítulo siguiente.

\section{Tipología de los anglicismos en narraciones deportivas costarricenses}

\subsection{El préstamo de vocabulario o léxico}

En este tipo de vocabulario se conserva tanto como sea posible la forma fónica de la palabra. Se dice tanto como sea posible, porque la reproducción exacta de una palabra extranjera es casi imposible de lograr.

\subsubsection{Préstamos de vocabulario}

$\begin{array}{ll}\text { Préstamo } & \text { Étimo } \\ \text { ausay } & \text { outside } \\ \text { bac } & \text { ball back } \\ \text { chut } & \text { shoot } \\ \text { conecte } & \text { connect }\end{array}$




$\begin{array}{ll}\text { espor } & \text { sport } \\ \text { faul } & \text { foul } \\ \text { faul } & \text { fault } \\ \text { fútbol } & \text { football } \\ \text { gol } & \text { goal } \\ \text { penal } & \text { penal } \\ \text { penalti } & \text { penalty } \\ \text { réferi } & \text { referee } \\ \text { reprís } & \text { reprise }\end{array}$

\subsection{Préstamos de raíces}

Consideramos necesario hacer la distinción entre préstamos de vocabulario y préstamos de raíces, en virtud de que entre ambos casos se establece una distinción a partir de aspectos morfológicos.

Los siguientes vocablos constituyen una subcategoría de los préstamos de vocabulario léxico; una raíz, tomada del inglés, mediante los procesos de derivación castellana, adquiere la condición de palabra castellanizada.

\section{Término español Raíz}

$\begin{array}{ll}\text { chutazo } & \text { shoot }+ \text { secuencia de sufijos -az-o } \\ \text { chuteador } & \text { shoot }+ \text { secuencia de sufijos -e-a-dor } \\ \text { chutear } & \text { shoot }+ \text { secuencia de sufijos -e-a-r } \\ \text { driblar } & \text { dribble + secuencia de sufijos -a-r } \\ \text { faulear } & \text { foul + secuencia de sufijos }-e-a-r\end{array}$

\subsection{Préstamo de formación}

En este tipo de préstamo se agrupan todas aquellas palabras que, influenciadas por un modelo extranjero, en este caso el inglés, han sido recreadas a partir de elementos lingüísticos propios. En esta categoría hay tres tipos: calcos de esquema, calcos un poco más libres frente al modelo y el préstamo de creación (Lüdtke 1974: 23). En el corpus de la presente investigación se encontraron únicamente calcos de esquema.

\subsubsection{Calcos de esquema}

En esta categoría, la traducción es exacta, se traduce palabra por palabra; el único cambio es que en algunos casos se invierten los miembros, de acuerdo con la morfología castellana.

$\begin{array}{ll}\text { balompié } & \text { football } \\ \text { guardameta } & \text { goalkeeper }\end{array}$




\subsection{Préstamo semántico}

El tercer tipo de préstamo, según Lüdtke, es el semántico: préstamos de significado. En esta categoría encontramos palabras que ya existen en castellano y, por influencia extranjera, amplían su significado con una acepción completamente diferente a la que tienen en esta lengua. Esa nueva acepción ha sido tomada de la lengua donante, el inglés en el presente caso, como por ejemplo:

$\begin{array}{ll}\text { conectar } & \text { connect } \\ \text { conexión } & \text { connection } \\ \text { evento } & \text { event } \\ \text { mano } & \text { hand } \\ \text { servicio } & \text { service } \\ \text { suceso } & \text { success }\end{array}$

\section{Diccionario}

\subsection{Inventario léxico}

A

ausay $m f b l$ Posición incorrecta de un jugador del equipo atacante que, estando en territorio contrario, recibe el balón con solo el portero como rival al frente. /2 Sanción que decreta el árbitro cuando un jugador está en posición prohibida. De offside por contaminación.

aut $m f b v b 1$ Lugar fuera de las líneas que delimitan el área de juego. De out.

\section{B}

bac $m f b 1$ Jugador de ---> fútbol que se sitúa delante del portero, y cuya misión es defender la propia meta [defensa].

balón $m f b$ Cuerpo esférico hecho de hule u otro material el cual es recubierto de cuero o material sintético, cuyo peso, tamaño y medidas están debidamente reglamentados [pelota, esférico]. De baloon. DRAE

\section{C}

club $m f b$ Grupo de personas asociadas con un propósito común, por lo general en una organización, que se reúne regularmente. De club. DRAE

chuteador $m f b$ Jugador que patea la pelota con gran fuerza y tino hacia la meta del equipo contrario. Derivado de chutear y este de to shoot.

chutear $v f b l$ Patear la pelota con mucha fuerza hacia la portería del equipo contrario . De 
to shoot.

cona $\mathrm{f} f b$ l Sanción que decreta el árbitro central cuando una pelota es sacada por la línea final de uno de los lados de la cancha por un jugador del equipo contrario al que tenía la pelota. /2 Lugar por donde debe ser puesta en circulación la pelota que fue sacada de juego [esquina, tiro de esquina]. De corner.

conectar $v$ fb 1 Pasar la pelota un jugador a otro. / 2 Hacer pases. De connect.

conexión $f f b$ Pase de pelota que hace un jugador con otro de su mismo equipo. De connection.

contusión $m b f b b b v b$ Golpe que recibe un jugador durante el juego. [lesión] Derivado de contusionar y este de contusion.

contusionado $a d j f b$ Golpeado, lesionado por un jugador durante el juego. Derivado de contusionar y este de contusion.

contusionar $v f b$ Causar daño físico por medio de un golpe [lesionar]. De contusion.

\section{D}

driblin $m f b$ Pase de la pelota, o fintas con ella, que hace un jugador para evitar la marcación de los jugadores del equipo contrario, y para mantener el control de la pelota. De dribbling.

driblar $v f b$ Pasar la pelota, y adelantarse un jugador contrario, mediante movimientos ágiles de su cuerpo. De to dribble.

dril $m b b$ Ejercicio que hace un equipo en grupo [práctica, entrenamiento]. De drill.

E

escor $m f b 1$ Número de puntos obtenidos por un equipo /2 Tablero en donde se anotan los puntos obtenidos por los equipos que están jugando [marcador]. De score.

espor $m b b f b v b$ Palabra que se usa para denominar todo lo que conlleva ejercicio físico [atletismo, ropa deportiva]. De sports.

están $m b b$ Gradería con bancos para los jugadores que no están jugando [gradería, banca]. De stand.

evento $m b b f b v b$ Espectáculo atlético [encuentro]. De event. 
faul $m f b b b l$ Infracción voluntaria o accidental que un jugador le comete a otro del equipo contrario. /2 Sanción decretada por el árbitro por faltas cometidas [falta]. De foul y fault por contaminación.

faulear $v f b$ Agredir o golpear, antirreglamentariamente, a un jugador del equipo contrario por accidente o adrede. De to foul.

futbol $m$ var fútbol $f b$ Práctica atlética, regida por normas precisas, en que dos equipos con once jugadores cada uno intentan meter la pelota en la meta del equipo contrario para anotarse ---> goles a su favor [balompié]. De football. DRAE.

fútbol ---> futbol. De football. DRAE.

$\mathbf{G}$

gol $m f b$ Punto a favor de un equipo cuando logra meter la pelota en la meta del equipo contrario [tanto, punto]. De goal. DRAE.

golazo $m f b$ Pelota que entra en la meta en forma extraordinaria, habilidosa. Derivado de gol y este de goal. DRAE.

goleador $m f b$ Jugador que logra meter muchos ---> goles. Derivado de golear. DRAE.

golear $v f b$ Meter la bola muchas veces en la meta del equipo contrario. Derivado de gol y este de goal. DRAE.

guardameta $m f b$ Jugador encargado de defender la meta de su equipo para evitar que le hagan goles en contra [portero, cancerbero]. De goalkeeper.

$\mathbf{J}$

jan $m f b$ Toque con la mano que le hace un jugador, que no es el portero, a la pelota fuera del área chica [mano]. De hand.

$\mathbf{M}$

mánayer $m b b$ Director del equipo cuya misión es preparar, dirigir y acompañar a los jugadores. De manager.

\section{$\mathbf{P}$}

penal $m \mathrm{fb} l$ Castigo que decreta el árbitro a un equipo, por cometer una falta grave dentro del área grande o de ---> penal, contra un jugador del equipo contrario, y que da derecho a patear la pelota frente a la meta a solo 11 metros de ésta, con la intervención del pateador y 
del portero del equipo castigado. /2 Forma de llegar a un desempate en competencias mundiales, luego de haber agotado los treinta minutos de juego adicional. De penalty.

penalty $m \mathrm{fb} l$ Castigo que decreta el árbitro a un equipo por cometer una falta grave dentro del área grande o de ---> penal, contra un jugador del equipo contrario, y que da derecho a patear la pelota frente a la meta a solo 11 metros de ésta, con la intervención del pateador y del portero del equipo castigado. $/ 2$ Forma de llegar a un desempate en competencias mundiales, luego de haber agotado los treinta minutos de juego adicional. De penalty.

\section{$\mathbf{R}$}

réferi $m f b$ Encargado de velar por el cumplimiento de las reglas del juego [árbitro, juez central, el hombre de negro]. De referee.

reprís $m f b$ Repetición de una jugada cuando el partido se está transmitiendo por la televisión [repetición]. De reprise.

S

servicio $m f b v b$ Saque que hace un jugador para poner la pelota en movimiento e iniciar o continuar con el juego [saque]. De service.

\section{Bibliografía}

A B C,XYZ del fútbol. 1971. Barcelona: Editorial Santos. S.A.

Alfaro, Ricardo. 1950. Diccionario de Anglicismos. Madrid: Editorial Gredos.

Carreter, Lázaro. 1969. Diccionario de Términos Filológicos. Madrid: Editorial Gredos.

Casares, Julio. 1942. Diccionario de la Lengua Española. Madrid: Editorial Gustavo Gil, S. A.

Corominas, J. 1980-1983. Diccionario Crítico Etimológico Castellano e Hispano. Madrid: Editorial Gredos S.A.

Cuervo, Rufino. 1983. Diccionario de Autoridades. Bogotá: Instituto Caro y Cuervo.

Cuyás, Arturo. 1980. Appleton's New English Spanish and Spanish English Diccionary. London: D. Appleton Century Co.

El Lenguaje (Diccionario de Lingüística). 1987. Bilbao: Ediciones Mensajero. 1987.

Enciclopedia Salvat de los Deportes Volúmenes 1 y 5. Barcelona: Salvat Editores, S.A. Gagini, Carlos. 1919. Diccionario de costarriqueñismos. San José: Imprenta Nacional. 
Haensch G., L. Wolf, S. Ettiner y R. Werner. 1982. La Lexicografía. Madrid: Editorial Gredos. 1986. "La situación actual de la lexicografía del español de América". Revista de Filología Románica, IV. Madrid: Editorial de la Universidad Complutense.

1985. "La selección del material léxico para diccionarios descriptivos". Philological Hispaniensia. In Honoren Ml. Alvar. II Ling. Madrid: Edit. Gredos.

Lapesa, Rafael. 1942/1980. Historia de la Lengua Española. Madrid: Escelicer.

Lüdtke, Helmut. 1974. Historia del léxico románico. Madrid: Editorial Gredos.

Mora Cárdenas, Zuray. 1985. Cristian Rodríguez, los anglicismos y el español de Costa Rica. Tesis.

Pulido, A. 1981. Estadística y técnica de la investigación. Madrid: Ediciones Pirámide S. A.

Real Academia Española. 1986. Diccionario de La Lengua Castellana. España: Calpe, S. A.,Vigésima Edición.

Real Academia Española. 1973. Esbozo de una Nueva Gramática de la Lengua Castellana. Madrid: Espasa-Calpe.

Roget Mark, Peter. 1947. Thesaurus of Words and Phrases. New York: Crosset \& Dunlop.

Salas Madrigal, Agustín. 1951. Historia del Deporte en Costa Rica. Costa Rica: Imprenta Falcó.

Sánchez Corrales, Víctor. 1986. "Estudios en Costa Rica sobre lengua castellana: de Gagini a Agüero". Revista de Filología y Lingüística de la Universidad de Costa Rica. XII (1).

1988. "Lexicografía del español en Costa Rica, visión crítica". Revista de Filología y Lingüística de la Universidad de Costa Rica. XIV (2).

Seco, Manuel. 1987. Estudios de lexicografía española. Madrid: Paraninfo S. A.

Spillner, Bernd. 1974. Lingüística y Literatura. Madrid: Editorial Gredos.

Vox Diccionario Inglés-Español-Español-Inglés. 1970. Segunda Edición. Barcelona: Talleres Bibliográficos S. A.

Webster's New Twentieth Century Diccionary of The English Language Unabridged. 1971. Cleveland, Ohio: The World Publishing Company, Second Edition.

Wotjak, Gerd. 1977. Investigaciones sobre la estructura del significado. Madrid: Editorial 


\section{Gredos.}

Zeloro Elias, Miguel de Toro y Emiliano Gómez. 1985. Diccionario del significado de la lengua castellana. París: Garnier Hermanos, Editores.

Zúñiga Tristán, Virginia. 1976. El anglicismo en el habla costarricense. San Pedro de Montes de Oca: Editorial Universidad de Costa Rica. 